\title{
Collaborative Librarianship
}

Volume 4 | Issue 3

Article 5

2012

\section{Holding Your Vendor's Feet to the Fire}

\author{
Lori Bowen Ayre \\ Galecia Group, lori.ayre@galecia.com
}

Follow this and additional works at: https://digitalcommons.du.edu/collaborativelibrarianship

Part of the Information Literacy Commons

\section{Recommended Citation}

Ayre, Lori Bowen (2012) "Holding Your Vendor's Feet to the Fire," Collaborative Librarianship: Vol. 4 : Iss. 3 , Article 5.

DOI: https://doi.org/10.29087/2012.4.3.05

Available at: https://digitalcommons.du.edu/collaborativelibrarianship/vol4/iss3/5

This Viewpoints is brought to you for free and open access by Digital Commons @ DU. It has been accepted for inclusion in Collaborative Librarianship by an authorized editor of Digital Commons @ DU. For more information, please contact jennifer.cox@du.edu,dig-commons@du.edu. 


\title{
Holding Your Vendor's Feet to the Fire
}

\author{
Lori Ayre (lori.ayre@galecia.com) \\ Principal Consultant, The Galecia Group
}

The nut. The bolt. When you go to the hardware store with a bolt in hand, you probably feel pretty confident that you'll be able to find the nut you need to tighten that bolt. When I hand over my bolt to my local Rex Ace Hardware man, he strides down a nearby aisle and within seconds, I've got my bolt's mate. It screws on perfectly. Do I care who made the bolt or the nut? I do not. This is because nuts and bolts have standard on sizes and threads. Any quarter inch nut will screw onto any quarter inch bolt.

That's how it should work with the nuts and bolts of library software - the integrated library system (ILS). But that isn't how it works at all. For various reasons, our library systems have evolved into Winchester Mystery Houses that require all sorts of special, and often expensive, adaptations to bolt anything onto them.

You've probably tried to implement a PC management or security system or installed selfcheck machines. If so, you would have used SIP2 (Standard Interchange Protocol). Maybe you've tried to link up to a broader resourcesharing system. If so, you would have used SIP2, and maybe NCIP2 (NISO Circulation Interchange Protocol; NISO = National Information Standards Organization). SIP2 and NCIP2 are established protocols that are meant to solve the nuts and bolts problem. SIP2 was $3 \mathrm{M}^{\prime}$ s attempt to develop a standard way to communicate with the ILS for the purposes of handling circulation transactions and authenticating patrons. NCIP2 is that and more. It also supports the exchange of information about items.

SIP2 and NCIP2 are both protocols that are composed of standardized messages. The protocol defines the questions that can be asked of the ILS and it defines how the information is exchanged between the ILS and any external program or device. Standardizing this exchange means that the ILS vendor need only develop support for SIP2 and NCIP2 once, and then any third party product is able to communicate with the ILS to perform important tasks. This saves money for the third party (3P) vendors that require information that is stored ONLY in the ILS. Having a standard interface that works with every ILS, theoretically, saves libraries money because it simplifies integration. It would, theoretically, make interfacing with the ILS plug-n-play thereby saving money and opening up opportunities for extending the ILS with other vendor partners.

But, the fact is, most ILS products are most definitely NOT plug-n-play when it comes to integration of 3P products. Vendors don't build support for all of the SIP2 messages into their systems - just their chosen few. Many don't provide support for NCIP2 at all. As a result, libraries often end up paying their ILS vendor or the third party vendor to develop customized interfaces to make the systems work together.

On top of not fully supporting SIP2, the vendors also charge you extra for it. To use the SIP2 protocol, you have to pay your ILS vendor for a license. At least one vendor actually charges not once for the SIP2 license, but for every 3P device that communicates to the ILS over their SIP2 interface.

Libraries pay the $3 \mathrm{P}$ vendors too, but not in the form of a license. Because the interfaces provided by vendors are not standardized, each $3 \mathrm{P}$ vendor needs to develop an interface for each ILS. This increases the cost of their product. It also creates complications and adds costs each time a library switches from one ILS to another and their $3 \mathrm{P}$ vendors have to rejigger everything all over again.

This all raises some questions in my mind. My first and second question about this situation goes to the ILS vendors: why isn't support for 
SIP2 and NCIP2 a standard feature of your ILS? That's a little bit like charging extra for an OPAC.

Second question to ILS vendors: if a library charges for a SIP2 interface, isn't it reasonable to expect support for all messages? Considering the cost you charge for SIP2 licenses, I think libraries deserve the full monty!

My third question is to libraries: why do you keep writing procurement documents that don't require full support for SIP2 and NCIP2 - the only interfaces that give you a way to efficiently use $3 \mathrm{P}$ products?

Sadly, the answer to the first two questions lies in the answer to the third. The reason ILS vendors don't provide full support for SIP2 and NCIP2 and the reason they charge ridiculous prices for what they do provide is because libraries haven't provided any meaningful incentive for them to do otherwise. Why not include requirements in ILS procurements that could save libraries tens of thousands of dollars (or more), hundreds of hours of staff time, and which may limit the library's options for add-ons?

My belief is that most libraries don't even know they are letting the vendors off the hook. They insert a vague SIP2 requirement in their RFP and if the ILS vendor has anything close to support for a message or two, they claim to meet the requirement. It's not until implementation that the inevitable costs and problems become evident. As a result, each $3 \mathrm{P}$ product has to be jerry-rigged to work with the ILS instead of being clicked on like a Lego tile. And, the Winchester Mystery House gets yet another addition.

It's time for libraries to hold the ILS vendor's feet to the fire and demand full support for both SIP2 and NCIP2. Support for all standard messages available in the SIP2 protocol will ensure that the library can choose the $3 \mathrm{P}$ product that best addresses their needs. It means libraries can count on being able to use their ILS to authenticate users and circulate material outside of the ILS. It saves libraries money and gives them more options.
NCIP2 ensures that your library can use an ILL or resource-sharing product efficiently. Without NCIP2, transactions done on the ILL side need to be duplicated in the ILS. With NCIP2, the software handles all of the rigamarole of creating temporary bib and patron records in the ILS, and then going back and cleaning them up after the transaction is completed on the ILL side. NCIP can save hundreds of staff hours in ridiculous and unnecessary data entry.

Next time you develop your ILS requirements document, demand support for all SIP2 and NCIP2 messages. If that feels too bold, make sure you require that your prospective ILS vendor guarantee support for all the messages that your existing $3 \mathrm{P}$ vendors require. Maybe that will force them to add a message or two to their SIP2 interface offering. And, make sure you negotiate how they charge for using that interface. I believe it should be included in the core ILS package, but if that seems too bold, make absolutely sure it is a one-time license fee, not a fee assessed for each connected device.

Standards and protocols create options beyond the ILS. It's no wonder the ILS vendors aren't so keen to provide them. They only will when libraries start demanding they do so. 